\title{
The Therapeutic role of Thymoquinone Bioactive Compound as Target Natural Product from Nigella sativa Loaded with Chitosan Nanoparticles on Schistosomiasis
}

\author{
Hend M. El-Menyawy ${ }^{1 *}$, Karima M. Metwally ${ }^{1}$, Ibrahim R. Aly ${ }^{1}$, Asmaa A. Abo Elqasem ${ }^{1}$, Alaa A. Youssef ${ }^{2}$ \\ ${ }^{1}$ Zoology Department, Faculty of Science, Al-Azhar University (Girls branch), Cairo, Egypt. \\ ${ }^{2}$ Environmental Research and Medical Malacology Department, Theodor Bilharz Research Institute, Giza, Egypt. \\ *Corresponding author: Hend M. El-Menyawy, Mobile: (+20) 0201019232739, E-Mail: hendmetwally.2059@ azher.edu.eg
}

\begin{abstract}
Background: Schistosoma mansoni is a trematode helminth responsible for liver fibrosis or cirrhosis.

Aim of the work: In the present work natural products Thymoquinone loaded with chitosan nanoparticle (TQ/ChNP)) (TQ/ChNP) were used to determine their therapeutic effect on $S$. mansoni infection.

Materials and methods: A total of 40 healthy Swiss albino mice, 20-25 g in weight, procured from Theodor Bilharz Research Institute (TBRI) Imbaba, Egypt's Schistosome Biological Supply Center (SBSC).

Results: The infected mice treated with TQ/ChNP showed a significant decrease in the total worm burden. Treatment with $\mathrm{TQ} / \mathrm{ChNP}$ had a highly significant effect on mature worm burden, TQ/ChNP in prophylactic and therapeutic doses significantly increased the mean number of dead ova in comparison to control. TQ/ChNP had a high decrease effect on ova count in intestinal tissue and a moderate reduction on ova count in hepatic tissue. Prophylactic dose gave a high reduction effect on ova count in intestinal tissue. As regards the size of hepatic granuloma, TQ/ChNP had the highest significant reduction on mean granuloma diameter with noticeable improvement of hepatic pathology. TQ/ChNP treated group showed observable improvement of liver pathology with mild degeneration and slight-sized fibrocellular. Conclusion: Based on the outcome of this study, TQ/ChNP proved to have potential bioactivity against $S$. mansoni adult stages and its potentiality in improving hepatic pathology. Efficacy of TQ/ChNP to postpone progression in chronic liver diseases must be considered as preventive medicine in patients with hepatic disorders.
\end{abstract}

Keywords: S. mansoni infection, Nigella sativa, (TQ/ChNP), Chitosan, Oogram, Granuloma formation.

\section{INTRODUCTION}

Schistosomiasis is considered the second destructive tropical disease in the world (after malaria) and it is the main cause of morbidity and mortality in developing African countries, including Egypt especially with distinct population groups ${ }^{(1)}$. It affects more than 799 million patients who are children at risk of contracting contracture ${ }^{(2)}$.

The pathology associated with $S$. mansoni results from the accumulation of eggs of the parasite in the tissues, causing hepatomegaly, and followed by extensive cirrhosis ${ }^{(3)}$. The granulomatous inflammatory reaction to trapped eggs in the liver has also been shown to cause oxidative tension. Chitosan's progressive nature aids in enhanced cellular contact, distribution, and penetration capability in heterogeneous environments. benign tumor ${ }^{(4)}$. Control programs depend mainly on praziquantel (PZQ) therapy ${ }^{(5)}$.

Nowadays, there is an increase in the use of antiparasitic drugs derived from natural plant sources ${ }^{(6)}$ to overcome and control schistosomiasis ${ }^{(7)}$. Abaza, ${ }^{(8)}$ reviewed all herbal treatments used for schistosomiasis, including Chinese medicine, carvacrol (essential oil of Origanum vulgare obtained from pepperwort), myrrh (oleo-gum-resin from Commiphora molmol), artemisinin derivatives insulated from Artemisia annua, curcumin (C. longa), quinine (Cinchona officinalis), quinine-deficient garlic extract (Allium sativum) and black seed (Nigella sativa). Nigella sativa is one of the hopeful alternative drugs of a plant origin that have an
anti-Schistosoma effect ${ }^{(\mathbf{9}, 11)}$. Based on the antiparasitic activity of medicinal plants and natural products, Ali $\boldsymbol{e t}$ $\boldsymbol{a l} .{ }^{(10)}$ test the anti-Schistosoma activity of Nigella sativa oil and/or the terrestrial Chroococcus turgidus.

Nanoparticles can act as drug carriers that can alleviate pharmacokinetics, increase bioavailability, and objective release with negligible toxic effects ${ }^{(\mathbf{1 2})}$. The large numeral of free amine groups presents in the chitosan backbone when related with other biodegradable polymers promotes binding of many bioactive agents to the polymer ${ }^{(13)}$. For these reasons, chitosan has been expansively investigated for its potential as an absorption enhancer across intestinal epithelium for bioactive agents such as TQ. Considering above mentioned advantages of chitosan it was chosen for encapsulating TQ powerfully. The high drugcarrying capacity and longer shelf life of chitosan compared with other biodegradable polymers ${ }^{(14)}$, also serves as an important reason for using chitosan as a nanocarrier in this study. Elawamy et al. ${ }^{(15)}$ estimated the value of loading $N$. sativa on chitosan nanoparticles (ChNPs) in the treatment of $S$. mansoni infection compared to praziquantel showed reduced in worm burden all groups concerning the control and $N$. sativa groups while a significant decrease occurred in oogram pattern and tissue egg loads reached reduction percentages more than $90 \%$ in $\mathrm{NC}$ and NCP groups. The apparent role of ChNPs in the improvement of bilharzial hepatic changes. Thus, ChNPs enhanced the effects of $N$. sativa as a therapy for schistosomal infection. 
So, In the present work natural products (thymoquinone bioactive compound from Nigella sativa loaded with chitosan nanoparticle) (TQ/ChNP) were used to determine their therapeutic effect on $S$. mansoni infection.

\section{MATERIALS AND METHODS}

\section{Thymoquinone:}

The thymoquinone-rich fraction was isolated from $N$. sativa seeds using a modified supercritical fluid extraction (SFE) technique, according to Norsharina et al. ${ }^{(16) .}$

Chitosan is a kind of chitin: (Deacetylation degree: 93\%) that was acquired from Sigma Aldrich in the United States.

TQ/ChNP preparation: The ionotropic gelation method was used to carry out the synthesis method ${ }^{(\mathbf{1 7})}$.

\section{The preparation of Nanochitosan:}

1- Different quantities of chitosan $(1,2,3 \mathrm{mg} / \mathrm{mL})$ were dissolved in an acetic aqueous solution.

2- At room temperature, dropwise $5 \mathrm{~mL}$ of chitosan solution was added to $2 \mathrm{~mL}$ of TPP solution while magnetic stirring (1000 rpm, 1 hour) was performed.

3- The opalescent suspension was created under identical circumstances as step two.

4- The nanoparticles were separated by centrifugation for 30 minutes at $20,000 \mathrm{~g}$ and $14^{\circ} \mathrm{C}$.

5- The freeze-dried nanoparticles were kept at $53^{\circ} \mathrm{C}$ for storage.

6- We measured the weights of freeze-dried nanoparticles.

7- The addition of chitosan solution to TPP solution containing $100 \mathrm{mg} / \mathrm{mL}$ quantities of thymoquinone and chitosan condensate resulted in 7thymoquinone-loaded nanoparticles.

8- Centrifugation at $20,000 \mathrm{~g}$ and $14^{\circ} \mathrm{C}$ for 30 minutes was done to remove 8-thymoquinone-loaded nanoparticles from the aqueous solution.

9- The supernatant was collected, and its free protein content was spectrophotometrically estimated at 595 $\mathrm{nm}$ according to the Bradford technique.

10- The following formulas were used to compute the encapsulation efficiency (AE) and loading capacity (LC) of nanoparticles:

$$
\begin{aligned}
& \% \mathrm{AE}=((\mathrm{A}-\mathrm{B}) / \mathrm{A}) \times 100 \\
& \% \mathrm{LC}=((\mathrm{A}-\mathrm{B}) / \mathrm{C}) \times 100
\end{aligned}
$$

Where A represents total thymoquinone, B represents free thymoquinone, and $\mathrm{C}$ represents the weight of nanoparticles.

\section{Experimental animals:}

A total of 40 healthy Swiss albino mice, 20-25 g in weight, were procured from Theodor Bilharz Research Institute (TBRI) Imbaba, Egypt's Schistosome Biological Supply Center (SBSC). They were fed a regular meal with a protein level of $24 \%$.

Also, Cercariae of Schistosoma mansoni were acquired from infected Biomphalaria alexandrina snail that maintained at Medical Malacolgy Laboratory, Theodor Bilharz Research Institute's TBRI ${ }^{(\mathbf{1 8})}$.

\section{Ethical approval:}

This study was conducted in accordance with ethical procedures and policies approved by Animal Care and Use Committee of Faculty of science, AlAzhar University, Cairo, Egypt.

\section{Experimental design:}

- The animals used in the present work were divided randomly into four groups (ten in each group):

- Group 1: served as the negative control group (noninfected/non-treated)

- The other three groups were infected with $80 \pm 10 \mathrm{~S}$. mansoni cercariae suspended in $0.2 \mathrm{ml}$ water via subcutaneous injection

- Group 2: served as the positive control group (Infected/non-treated)

- Group 3: Infected and treated with Chitosan (200mg $/ \mathrm{kg}$ ) 3 times every week at $4^{\text {th }}$ week of infection for 4 weeks.

- Group 4: Infected and treated with TQ/ChNP $(200 \mathrm{mg} / \mathrm{kg}) 3$ times every week at $4^{\text {th }}$ week of infection for 4 weeks.

- All mice were sacrificed after the $8^{\text {th }}$-week postinfection.

Worm Burden: The Porto-mesenteric perfusion technique was used to measure adult schistosome recovery according to Duvall and DeWitte ${ }^{(19)}$.

Oogram pattern: To assess ova development and viability and to represent medicinal activity on oviposition and maturation.

Three small intestinal segments (each $1 \mathrm{~cm}$ long) were sliced lengthwise after perfusion, cleaned in saline, partially dried on filter paper, and then squeezed between two glass slides. Each piece was counted for a hundred eggs as a rule, and the process was repeated with other fragments until a total of 300 eggs were retrieved and classified into three types: immature, mature, and dead ${ }^{(20)}$.

\section{Egg count:}

Small pieces of infected mice's liver and intestine (ileum) were incubated overnight in 4 percent potassium hydroxide $(\mathrm{KOH})$ as reported ${ }^{(21)}$, then centrifuged for 10 minutes at 200 g. 251 from each sample was placed in a flat bottom plate (Coaster) for counting the eggs in the liver and intestine, then $25 \mu \mathrm{l}$ from each sample was placed in a flat bottom plate (Coaster) for counting the eggs in the liver and intestine. Knowing the weights of the liver and intestine may be used to compute the total egg count in infected mice's liver and intestine.

\section{Histopathological examination:}

The liver was extracted and fixed in $10 \%$ buffered 
formalin solution for 48 hours, then washed, dried, cleared, and paraffin slices $(5 \mu)$ were produced. Using a rotary microtome, serial slices were cut at a thickness of $5 \mu$. Sections were hydrated, dyed, and stained with hematoxylin and eosin (HE) according to Bancroft and Stevens' procedure ${ }^{(22)}$, then microscopically examined and photographed.

For measuring, granulomatous lesions with a single ovum in the center the largest diameter of the lesion was measured using the ocular micrometer, then turned 90 degrees and the perpendicular diameter was measured. On the premise that each liver granuloma was spherical, the size of each granuloma was determined using the mean diameter of each lesion ${ }^{(23)}$. Granulomas were counted in five different fields for each party $(10 \times 10)$.

\section{Statistical analysis}

The data are presented as means and standard deviations. The T-test analysis values of $\mathrm{p} 0.05$ were declared statistically significant by employing a oneway analysis of variance (ANOVA). In addition, the Microsoft Office Excel application and the GraphPad InStat 3 program were used ${ }^{(24)}$.

\section{RESULTS}

The results presented in Table (1) showed that $\mathrm{TQ} / \mathrm{ChNP}$ treated group has a low significant effect on the mean number of total mature worm burden ( $\mathrm{R}$ $60.860 \%$ ), Where the effect of the Chitosan group showed a less significant effect of other groups (R $33.755 \%$ ) compared with the control group.

$\mathrm{TQ} / \mathrm{ChNP}$ showed a highly significant effect on the reduction rate of couples followed by chitosan ( $R$ $53.654 \%$ \& R 9.849\% respectively) compared with the control group. The mean number of male worms is more than the mean number of female worms in the control group ( $9 \& 7.167$ respectively). This result was also observed in TQ/ChNP while chitosan treated groups found that the mean number of female worms is more than the mean number of male worms. All treated groups showed a low significant effect on the mean number of male worms.

Table (1): Infection of albino mice with $S$. mansoni cercariae exposed to chitosan \& (TQ/ChNP) on worm burden in $S$. mansoni infected mice.

\begin{tabular}{|c|c|c|c|c|}
\hline \multirow[b]{2}{*}{ Groups } & \multicolumn{4}{|c|}{ Mean mature worm burden (\% reduction) } \\
\hline & $\begin{array}{l}\text { Couple } \\
(\mathbf{R} \%)\end{array}$ & \begin{tabular}{|l|} 
Male \\
$(\mathrm{R} \%)$ \\
\end{tabular} & $\begin{array}{r}\text { Female } \\
(\mathrm{R} \%) \\
\end{array}$ & \begin{tabular}{|c|} 
Total worm \\
$(\mathbf{R} \%)$
\end{tabular} \\
\hline $\begin{array}{l}\text { Infected } \\
\text { control }\end{array}$ & $\begin{array}{l}6.833 \pm \\
0.7528\end{array}$ & $\begin{array}{l}9.000 \pm \\
0.8944\end{array}$ & $\begin{array}{c}7.167 \pm \\
1.169\end{array}$ & $\begin{array}{c}27.67 \pm \\
3.83\end{array}$ \\
\hline \begin{tabular}{|l|} 
Chitosan \\
\end{tabular} & $\begin{array}{c}6.167 \pm \\
1.602 \\
(9.849 \%) \\
\end{array}$ & $\begin{array}{c}3.000 \pm \\
1.673 * * * \\
(66.667 \%)\end{array}$ & $\begin{array}{c}3.333 \pm \\
1.862 * \\
(53.497 \% \\
\end{array}$ & $\begin{array}{c}18.33 \pm \\
1.033 * * * \\
(33.755 \%)\end{array}$ \\
\hline $\begin{array}{c}\text { TQ/ } \\
\text { ChNP }\end{array}$ & $\begin{array}{c}3.167 \pm \\
1.941 * * \\
(53.654 \%\end{array}$ & $\begin{array}{c}2.833 \pm \\
2.483 * * * \\
(68.522 \%)\end{array}$ & $\begin{array}{c}2.00 \pm \\
2.00 * * \\
(\mathbf{7 2 . 0 9 5 \% )}\end{array}$ & $\begin{array}{c}10.83 \pm \\
0.983 * * * \\
(60.860 \%)\end{array}$ \\
\hline
\end{tabular}

$* \&^{* * *} \& * * *$ significant compared to control value at $p<0.05 \& p<0.01 \& p<0.001$ respectively.

Data obtained from Table (2) on the effect of chitosan and thymoquinone bioactive compound from $N$. sativa loaded with chitosan nanoparticle (TQ/ChNP) on the mean number of (ova/gram) on hepatic tissue and intestinal tissue of $S$. mansoni infected mice induced that the ova count in hepatic tissues is more than the ova count in intestinal tissues in all treated groups and control group. The highest significant decrease in the mean number of (ova/gram) on hepatic tissue and intestinal tissue was observed on all treated groups $(\mathrm{P}<0.001)$. The most evident reduction in the ova count ova/gm of both hepatic and intestinal tissues is in the group treated with TQ/ChNP therapy (R 73.295\% \& R $72.89 \%$ respectively). In the present work, the lowest reduction percentage in ova count/gram of intestinal tissue was in the chitosan group (R 28.37\%) and reached (R 52.944\%) in hepatic tissue as compared with control.

Table (2): Effect of chitosan and (TQ/ChNP) on the mean number of (ova/gram) on hepatic tissue and intestinal tissue of $S$. mansoni infected mice.

\begin{tabular}{|c|c|c|c|c|}
\hline Groups & $\begin{array}{c}\text { No of } \\
\text { ova/gram } \\
\text { hepatic } \\
\text { tissue }\end{array}$ & $\begin{array}{c}\text { Reduction } \\
\% \\
(\mathbf{R} \%)\end{array}$ & $\begin{array}{c}\text { No of } \\
\text { ova/gram } \\
\text { intestinal } \\
\text { tissue }\end{array}$ & $\begin{array}{c}\text { Reduction } \\
\% \\
(\mathbf{R} \%)\end{array}$ \\
\hline $\begin{array}{c}\text { Infected } \\
\text { control }\end{array}$ & $\begin{array}{c}\mathbf{9 1 0 0} \\
\pm \mathbf{4 8 5 . 8}\end{array}$ & $-\cdots---$ & $\mathbf{2 6 5 0 \pm}$ & $\cdots$ \\
\hline Chitosan & $\begin{array}{c}\mathbf{4 3 1 7} \\
\pm \mathbf{2 2 2 . 9} * * *\end{array}$ & $\mathbf{5 2 . 9 4 4 \%}$ & $\mathbf{1 3 7 . 8}$ & \\
\hline TQ/ChNP & $\begin{array}{c}\mathbf{2 4 5 0} \\
\pm \mathbf{3 0 8 . 2} * * *\end{array}$ & $\mathbf{7 3 . 2 9 5 \%}$ & $\mathbf{2 3 6 . 6} * * *$ & $\mathbf{2 8 . 3 7 0 \%}$ \\
\hline
\end{tabular}

***significant compared to control value at $\mathrm{p}<0.001$

In the oogram pattern, $\mathrm{TQ} / \mathrm{ChNP}$ treated group gave a highly significant increase in the mean of dead ova $(82.33 \pm 4.082)$ (which is 71 times as the control) and a highly significant decrease in the percentage of mature ova $(8.50 \pm 5.648)$, while it does not affect immature ova

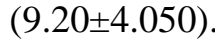

Chitosan group showed a significantly increased percentage of dead ova $(8.000 \pm 1.789) 6.8$ times as control but, without a significant effect on mature $(50.00 \pm 11.03)$ and immature ova $(42.00 \pm 9.466)$ as seen in Table (3).

Table (3): Effect of chitosan and (TQ/ChNP) on oogram pattern in intestinal segments of $S$. mansoni infected mice.

\begin{tabular}{|c|c|c|c|}
\hline \multirow{2}{*}{ Groups } & \multicolumn{3}{|c|}{ Egg types Mean \pm SD } \\
\cline { 2 - 4 } & Immature & Mature & Dead \\
\hline $\begin{array}{c}\text { Control } \\
\text { infected }\end{array}$ & $37.17 \pm 7.250$ & $61.67 \pm 6.055$ & $1.167 \pm 1.602$ \\
\hline Chitosan & $42.00 \pm 9.466$ & $50.00 \pm 11.03$ & $\mathbf{8 . 0 0 0} \pm 1.789 *$ \\
\hline TQ/ChNP & $9.20 \pm 4.050 * * * 8.50 \pm 5.648 * * * 82.33 \pm 4.082 * * *$ \\
\hline
\end{tabular}

$* \& * * *$ significant compared to control value at $\mathbf{p}<0.05 \&$ p $<0.001$ respectively.

Data obtained from Table (4) showed the effect of chitosan and thymoquinone bioactive compound from $N$. sativa loaded with chitosan nanoparticle (TQ/ChNP) 
on mean number and diameter of hepatic granuloma in S. mansoni infected mice and control group. The highest significant decrease in the mean number of hepatic granulomas on all treated groups $(\mathrm{P}<0.001)$. The most evident reduction in the mean number of hepatic granulomas is in the group treated with $\mathrm{TQ} / \mathrm{ChNP}$ therapy (R71.83 \%). In the present work, the lowest reduction\% in the mean number of hepatic granulomas was in the chitosan group (R 40.84) compared with the control that record $17.75 \pm 2.062$ hepatic granuloma in the ten fields.

The mean granuloma diameter and percentages of reduction in its diameter were detected in the liver sections from all groups of mice included in this study. The liver of all treated groups showed significant decreases $(p<0.05)$ in the area of fibrosis as compared with the control group, liver sections of the group treated with $\mathrm{TQ} / \mathrm{ChNP}$ therapy showed a significant decrease in granuloma diameter $(65.5 \pm 16.54)$ while the non-significant reduction was observed in the liver of chitosan group treatment $(119.1 \pm 32.60)$ in comparison with the control group (125.6 \pm 20.88$)$.

In-state of eggs pattern, TQ/ChNP treated group gave a high increase on mean percentage of degenerated ova $(90 \%)$ (which is $5 \%$ in the control group) and decrease on the percentage of intact ova $(10 \%)$. The chitosan-treated group showed an increased percentage of degenerated ova (73\%) and decreased percentage of intact ova (27).

Table (4): Effect of chitosan and (TQ/ChNP) on mean number and diameter of hepatic granuloma and types and state of eggs in S. mansoni infected mice.

\begin{tabular}{|c|c|c|c|c|}
\hline \multirow[t]{3}{*}{ Groups } & \multicolumn{4}{|c|}{ Mean hepatic granuloma } \\
\hline & \multirow{2}{*}{$\begin{array}{c}\text { Mean number } \\
\text { of granuloma } \\
(\mathrm{R} \%)\end{array}$} & \multirow{2}{*}{$\begin{array}{c}\text { Mean } \\
\text { diameter of } \\
\text { granuloma in } \\
(\mu \mathrm{m})(\mathrm{R} \%)\end{array}$} & \multicolumn{2}{|c|}{ State of eggs (\%) } \\
\hline & & & Intact & Degenerated \\
\hline $\begin{array}{l}\text { Control } \\
\text { infected }\end{array}$ & $17.75 \pm 2.062$ & $125.6 \pm 20.88$ & 95 & 5 \\
\hline Chitosan & $\begin{array}{c}10.50 \pm 1.732 * * \\
(40.84 \%)\end{array}$ & $\begin{array}{c}119.1 \pm 32.60 \\
(5.170 \%)\end{array}$ & 27 & 73 \\
\hline \begin{tabular}{|l|} 
TQ/ \\
ChNP
\end{tabular} & $\begin{array}{c}5.00 \pm 1.826 * * * \\
(71.83 \%)\end{array}$ & $\begin{array}{c}65.5 \pm 16.54 * * * \\
(47.850 \%)\end{array}$ & 10 & 90 \\
\hline
\end{tabular}

\section{Histopathological results}

Examination of sections obtained from the liver of the control group (non-infected non-treated) showed normal histological structure. The liver was formed of classic hepatic lobules which were roughly hexagonal with central veins forming their central axis. At their angles, portal areas were containing connective tissue stroma and portal triads. The latter consisted of a terminal branch of the hepatic artery and a small branch of the portal vein as well as bile ductile. Blood sinusoids were found as a network between the plates of hepatocytes converging toward the central vein. They were lined by two types of cells, the endothelial, and Kupffer cells. The endothelial cells appeared flattened forming a discontinuous layer with darkly stained flat nuclei and Kupffer cells appeared scattered among the endothelial cells with large, rounded nuclei Plate 1(a).

On the other hand, histopathological changes in liver sections of infected untreated mice are preserved hepatic architecture with multiple portal andparenchymal granulomas (fibroblast and granulocyte) around ovum of variable sizes and shapes are clear in shown in Plate1 (b) and portal fibrosis due to massive and concentrated deposition of eggs in portal areas, whereas the liver parenchyma maintains its normal architecture. Irregularly outlined and cellular granulomas composed of lymphocytes, histiocytes, epitheliod cells, and eosinophils surrounding recently deposited intact eggs could be observed and exhibiting large fibrocellular granuloma with irregular outlines and excess inflammatory cells admixtured with collagenous fibrous tissue also migration of infiltrative cells including lymphocytes, monocytes and eosinophils Plate 1(c). In addition to widely expanded and congested hepatic portal veins which contain hemolytic blood cells. In addition to the diffuse portal cell infiltration, there was intralobular focal and diffuse cell infiltration and proliferation with high skin wall of bile duct Plate 1 (c).

On the other hand, inflammatory cell infiltrate the portal tract and some hepatocytes show vacuolated cytoplasm with pyknotic nuclei Plate 1 (d).

Infected mice subjected to chitosan show multiple fibrocellular granulomas around more than one preserved ovum. Marked congestion and dilatation of central veins and hepatic sinusoids occurred with portal tract expansion and marked lobular inflammation around affected hepatocytes with loss of normal liver architecture. In addition to the diffuse portal cell infiltration with irregularly outlined and cellular granulomas (mass small granulomatous area) around the hepatic portal and found degenerated hepatocytes also some karyomegalic cells and thickening of the wall of portal tract blood vessels Plate 2 (a\&b).

Infected mice subjected to TQ/ChNP show fewer numbers of fibrocellular granulomas with distorted ova. Hepatic architecture showed moderate improvement and lobular inflammation and with more collagen deposition revealed some dead ova among also, granuloma area become cirrhosis area surrounded by fibroblast and granulocyte and marked reduction was noticed Plate 3 (c). Hepatic architecture showed moderate improvement with lesser expansion of portal tracts Plate $3(\mathbf{d})$. 


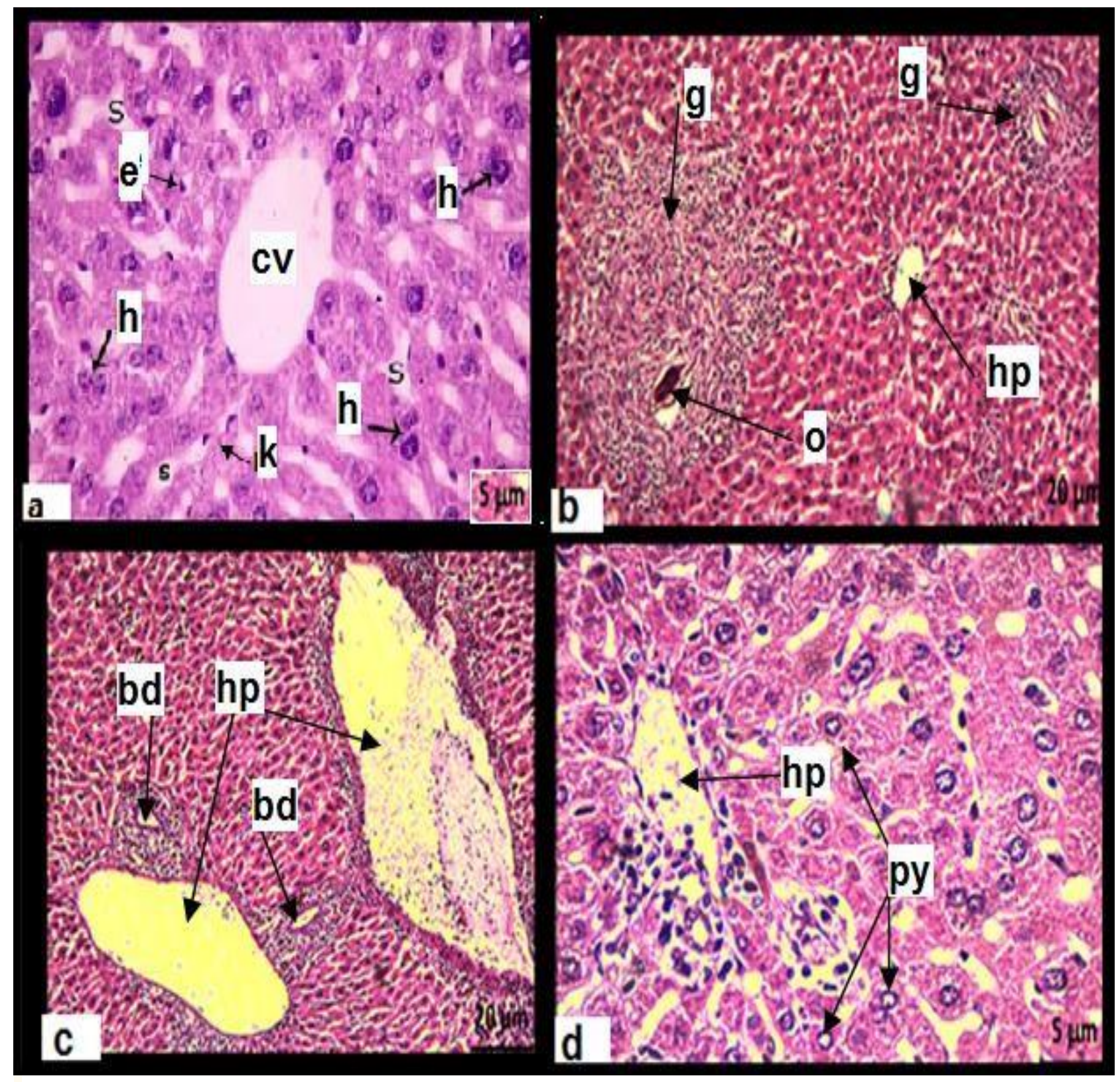

Plate (1): Transverse section (T.S.) in the liver of mouse (hematoxylin and eosin) showing:(a): Photomicrographs of liver sections of control group showing: Normal liver architecture, a classic hepatic lobule-containing central vein (cv), and radiating cords of hepatocytes with blood sinusoids (s) in between. Polyhedral hepatocytes with large, rounded vesicular nuclei (h) and prominent nucleoli, some binucleated cells are also present, blood sinusoids (s) are present in between the cords of hepatocytes and are lined by flattened endothelial cells (e) and Kupffer cells (k). (b): showing: Preserved hepatic architecture with multiple portal and parenchymal granulomas (g) (fibroblast and granulocyte) of variable sizes and shapes is clear surrounded the ova $(\mathrm{O})$. (c): showing: dilated and congested hepatic portal veins (hp) which contain hemolytic blood cells and proliferation with highly skin wall of the bile duct (bd). (d): showing: inflammatory cell infiltrate in the portal tract and some hepatocytes show vacuolated cytoplasm with pyknotic nuclei (py) in infected mice. 


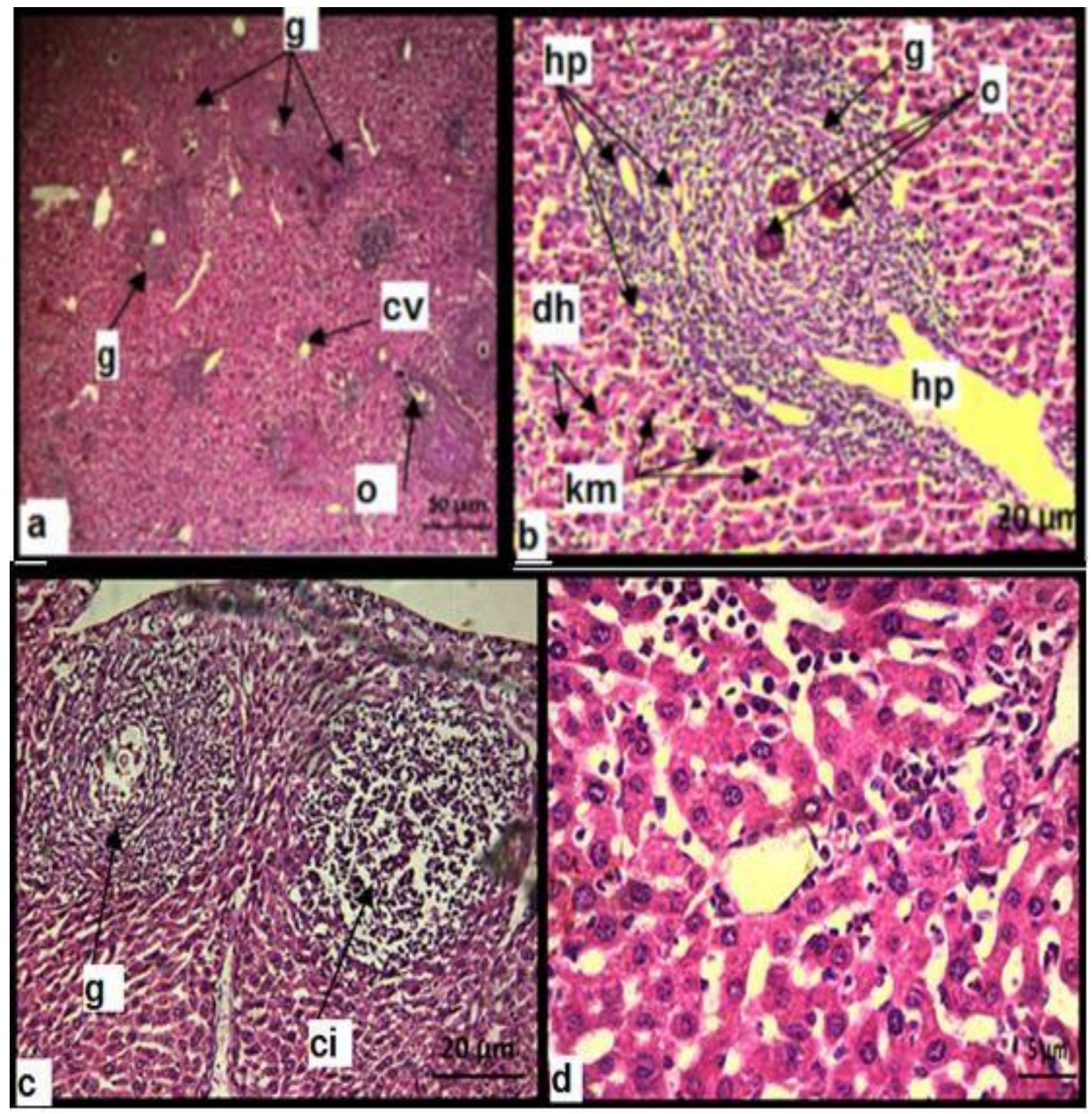

Plate (2): Transverse section (T.S.) in the liver of mouse (hematoxylin and eosin) showing: (a): Photomicrographs of liver sections of infected mice treated with chitosan showing: multiple fibrocellular granulomas $(\mathrm{g})$ around more than one preserved ovum (o). Marked congestion and dilatation of central veins (cv) and hepatic sinusoids with portal tract expansion and marked lobular inflammation around affected hepatocytes with loss of normal liver architecture were noticed. (b): many fibrocellular granulomas and cellular granuloma (g) with sound ova (o) in their centers and collagen deposition around the ova cells and irregularly outlined and cellular granulomas (mass small granulomatous area) around hepatic portal and degenerated hepatocytes (hd) found and some karyomegalic cells (km) in the liver sections of infected mice treated with chitosan. (c): Photomicrographs of liver sections of infected mice treated with TQ/ChNP showing: fewer numbers of fibrocellular granulomas (g) with distorted ova (do). Hepatic architecture showed and with more collagen deposition moderate improvement and lobular inflammation revealed some dead ova among also, destroyed the granuloma area (cirrhosis (ci) and marked reduction. (d): hepatic architecture showed moderate improvement with lesser expansion of portal tracts in the liver sections of infected mice treated with TQ/ChNP. 


\section{DISCUSSION}

Schistosomiasis is a chronic parasitic disease caused by blood flukes of the Schistosoma genus that annually infects more than 230 million people worldwide. This is why it is considered the largest important human parasitic disease in tropical regions (25). Infection with this organism affects intestinal and hepatic schistosomiasis in more than 100 million individuals that primarily live in sub-Saharan Africa, the Caribbean, and South American areas, including Brazil ${ }^{(26)}$. There is an ongoing need to develop alternative drugs to overcome schistosomiasis (26). Abaza ${ }^{(8)}$ Reviewed all herpes that was used in the treatment of schistosomiasis excluding black seed (Nigella sativa) and other several native plants from Brazil. The essential oil of $N$. sativa is one of the promising alternative drugs of plant origin that have antischistosomal effects ${ }^{(11)}$. Nanostructures can cross the cell wall and tissue barriers as their particle size are very small, this makes them widely applicable in biomedical sciences ${ }^{(\mathbf{1 8})}$.

This study aimed to assess the therapeutic effect and microscopic changes of thymoquinone bioactive compound from $N$. sativa loaded with chitosan nanoparticle on adult $S$. mansoni in vitro. In present study by using chitosan alone and Thymoquinone loaded with chitosan nanoparticle (TQ/ChNP) to highlight the importance of treatment of $S$. mansoni infections in experimental mice with Thymoquinone loaded with chitosan nanoparticle (TQ/ChNP) which is a novel issue. The total worm burden was reduced by $60.860 \%$ in the TQ/ChNP group while chitosan treated groups found that the mean number of female worms is more than the mean number of male worms. All treated groups showed a low significant effect on the mean number of male worms. Present results were near to that of Sadek et al. ${ }^{(27)}$ regarded on total worm loads reduction of PZQ/CS-NPs (93\%) and CS-NPs (R 64\%) while PZQ alone recorded ( $\mathrm{R} 81 \%$ ) compared to the control group $(\mathrm{p}<0.01)$.

Ali et al. ${ }^{(10)}$ revealed a decrease of both female and male worm burdens by 41 and $64 \%$ respectively in $N$. sativa oil treatment while in contradiction of combined treatment which shown decrease by 21 and $49 \%$ respectively, this highlights the importance of loading N. sativa on ChNPs in that preparation which caused a drop of all worms.

In the same consequence, Elawamy et al. ${ }^{(15)}$ found that the total worm burden was compact by $66.3 \%$ in the NS group; by $77.5 \%$ in the NC group while all worms were damaged in the NCP group. Results in this study explain that there was the highest significant decrease in the mean number of (ova/gram) on hepatic tissue and intestinal tissue observed on all treated groups showed significant decreases found the mean number of (ova/gram) on hepatic tissue and intestinal tissue of $S$. mansoni infected mice induced that the ova count in hepatic tissues are more than the ova count in intestinal tissues in all treated groups and control group and this agrees with Ali et al. (10). Significant reductions of $56 \%$ followed by $65 \%$ and $74 \%$ in the numeral of eggs in liver tissue per gram were detected from mice treated with algal extract, or that treated with oil, or that treated with both algal extract and oil. The present study found that reduction in the ova count ova/gm of both hepatic and intestinal tissues in the group treated with $\mathrm{TQ} / \mathrm{ChNP}$ therapy (R $73.295 \%$ \& R $72.89 \%$ respectively). This agrees with Sadek et al. ${ }^{(27)}$ who found similar results about worm load, achieved the highest percentage of both intestine and liver egg load reduction a statistically significant difference between both groups $(\mathrm{p}<0.001)$ treatment with PZQ/CS-NPs (R 79\% \& R 86\%) or CS-NPs (R $70 \%$ \& R $60 \%$ ) or loaded with PZQ (R 74\% \& R 72\%) respectively. Also, Cheever ${ }^{(21)}$ showed NS/ChNPs a reduction in liver egg load by $84.5 \%$ and intestine egg load by $67.8 \%$ from the control mice.

In the current study, TQ/ChNP treated group which gave a highly significant increase in mean of dead ova (43.33 \pm 4.08$)$ (which is 37 times as the control) and a highly significant decrease in the percentage of mature ova (34.0 \pm 4.05$)$, while it does not affect immature ova $(34.00 \pm 10.7)$ Chitosan group showed significantly increased percentage of dead ova $(8.000 \pm 1.789) 6.8$ times as control but, without significant effect on mature $(50.00 \pm 11.03)$ and immature ova (42.00 \pm 9.466$)$. This result is confirmed by Abououf et al. ${ }^{(28)}$ used N. sativa oil alone against mature worms, the dead eggs increased from 5.25 to $21.4 \%$ of oogram pattern and immature eggs decreased from 62.5 to $31 \%$ of oogram in the untreated mice group while our results relying on NS/ChNPs achieved more treating effects as mentioned above, that proving the highly effective ChNPs as drug delivery system in the treatment of $S$. mansoni mature worms. In another study, dead eggs increased from 9 to $16 \%$ of oogram in $S$. mansoni infected mice when treated with a mixture of $N$. sativa oil and aqueous garlic extract and immature eggs decreased from 54 to $20 \%$ of oogram pattern in the same group of mice ${ }^{(29)}$.

The most evident reduction in the mean number of the hepatic granuloma in the treated group with TQ/ChNP therapy (R71.83\%) compared with the control that record $17.75 \pm 2.062$ hepatic granuloma in the ten fields and was in the chitosan group (R 40.84). Comparing our results with Sadek et al. ${ }^{(27)}$ recorded reduction number of hepatic granulomas that was subsequently the highest reduction followed by traditional PZQ/CS-NPs (R 85\%) or CS-NPs (R 85\%) or loaded with PZQ (R 72\%) treatment when compared to control group $(\mathrm{p}<0.01)$. Elawamy et al. ${ }^{(15)}$ observed regarding the hepatic granuloma formed by $S$. mansoni, NS/ChNPs showed excellent efficacy in treating bilharzial hepatic alterations by reducing 
granuloma diameter by 46.3 percent and demonstrating excellent efficacy of NS/ChNPs in improving bilharzial hepatic alterations. In schistosome infections, the formation of granuloma surrounding schistosome eggs in the liver is the major source of disease. This highly endemic parasite infection appears to be primarily responsible for death and morbidity through granuloma and subsequent fibrosis in the liver. Schistosomiasis damages the liver, generating granuloma development and hepatic fibrosis, according to histological findings. In the second month after infection, schistosomiasis produces necrotic alterations in the liver tissues. The delayed hypersensitivity reaction caused by egg-secreted soluble antigens causes tissue granuloma surrounding Schistosoma ova ${ }^{(30)}$. After a specialized therapy for parasites, the parasites are eliminated ${ }^{(31)}$.

Thus, the small-sized granulomas detected in liver sections of treated mice with $\mathrm{TQ} / \mathrm{ChNP}$ can be explained by the loss of the ability of the eggs to induce inflammatory reaction also, the area of granuloma was degenerated and replaced by cirrhosis area may be after that absorbed and replaced by hepatic tissue. The treated worms lay poorly developed eggs with reduced or even no ability to induce granuloma formation ${ }^{(32)}$. Decreased number of granulomas was following diminished egg counts in the liver and intestinal tissues and could be attributed to the elimination of adult worms by drug administration and consequently decreased egg deposition leading to sustained diminution of eggs induced immunopathology ${ }^{(33)}$. However, Sheir et al. ${ }^{(34)}$ reported that noninfected mice treated with $N$. sativa oil showed abnormal liver cells with pyknotic nuclei and cytoplasmic vacuolization.

In the present work, a great improvement in the histopathological aspects in infected mice treated with $\mathrm{TQ} / \mathrm{ChNP}$ caused a reduction in granuloma count and granuloma diameter. The improvement of the histopathological situation of the liver was evidenced by the decreased number and size of granuloma and the disappearance of pathological changes in hepatocytes (35). There was circumscribed round granuloma formation in the hepatic tissue with centrally located ova surrounded by abundant collagen, less cellular granulomatous area, and leucocytes diffuse kupffer cells proliferation in between the degenerated hepatocytes with normal histological collagen fibers.

\section{CONCLUSION}

Based on the outcome of this study, TQ/ChNP proved to have a potential bio-activity against $S$. mansoni adult stages and its potentiality in improving hepatic pathology. Efficacy of $\mathrm{TQ} / \mathrm{ChNP}$ to postpone progression in chronic liver diseases must be considered as preventive medicine in patients with hepatic disorders.
Acknowledgments: Authors thank the Theodor Bilharz lab scientific and technical staff for caring for animals and making specimens available for processing.

Funding sources: This research did not receive any specific grant from funding agencies in the public, commercial, or not-for-profit sectors.

Conflict of interest: The authors declare that there is no Conflict of interest. The authors alone are responsible for the content and writing of this article.

Ethical use of animals in research: All applicable international, national, and institutional guidelines for the care and use of animals were followed. We respected the welfare of animals and excluded situations when animals were in pain.

\section{REFERENCES}

1. Gouveia M, Brindley P, Rinaldi G et al. (2019): Combination anthelmintic/antioxidant activity against Schistosoma mansoni. Biomol., 9, 2:54-8.

2. WHO (2018): Schistosomiasis Fact Sheet, Geneva, Switzerland. https://www.who.int/news-room/factsheets/detail/schistosomiasis

3. Gryseels B, Polman K, Clerinx J et al. (2006): Human schistosomiasis. Lancet, 368: 1106-1118.

4. Agrawal S, Ahmad H, Dwivedi M (2016): PEGylated chitosan nanoparticles potentiate repurposing of ormeloxifene in breast cancer therapy'. Nanomedicine, 11: (16), 2147-2169.

5. Sokolow S, Wood C, Jones I et al. (2016): Global assessment of schistosomiasis control over the past century shows targeting the snail intermediate host works best. PLoS Negl Trop Dis., 10:4794.

6. Magalhães L, Machado C, Morais E et al. (2009): In vitro schistosomicidal activity of curcumin against Schistosoma mansoni adult worms. Parasitol Res., 104: 1197-1201.

7. John A, Tinuade A, Oyeku A et al. (2007): Effectiveness of Dried Carica papaya Seeds Against Human Intestinal Parasitosis: A Pilot Study. J Med Food, 10: 194-196.

8. Abaza S (2013): Treatment of schistosomiasis: From Praziquantel to development of new drug targets. Journal of Egyptian Parasitology, 6:127-148.

9. Tantawi H, Mostafa O (2003): Experimental use of black-seed oil against Schistosoma mansoni in albino mice. III. Ultrastructural studies of the liver. Egyp J Zool., 40: 27-45.

10. Ali M, Abou-Eldahab M, Mansour H et al. (2016): Schistosoma mansoni: Anti-parasitic effects of orally administered Nigella sativa oil and/or Chroococcus turgidus extract. Acta Biol Hungarica, 67, 3:247-60.

11. Mohamed A, Metwally N, Mahmoud S (2005): Sativa seeds against Schistosoma mansoni different stages. Memórias do Instituto Oswaldo Cruz, 100(2):205-211.

12. Khalil N, de Mattos A, Carraro T et al. (2013): Nanotechnological strategies for the treatment of neglected diseases. Current Pharmaceutical Design, 
19(41):7316-7329.

13. Unsoy G, Yalcin S, Khodadust R (2012): Synthesis optimization and characterization of chitosan-coated iron oxide nanoparticles produced for biomedical applications. J. Nanoparticle Res., 14(11): 1-13.

14. Tang Z, Qian J, Shi L (2007): Preparation of chitosan nanocapsules as a carrier for immobilized enzyme. Appl Biochem Biotechnol., 136: 77-96.

15. Elawamy W, Mohram A, Naguib $M$ et al. (2019): Therapeutic role of chitosan nanoparticles in murine schistosomiasis mansoni. J Med Plants Res., 13(18): 443-451.

16. Norsharina I, Maznah I, Aied A et al. (2011): Thymoquinone rich fraction from Nigella sativa and thymoquinone are cytotoxic towards colon and leukemic carcinoma cell lines. J Med Plants Res., 5: 3359-66.

17. Ohya Y, Shiratani M, Kobayashi H et al. (1994): Release behavior of 5-fluorouracil from chitosan-gel nanospheres immobilizing 5-fluorouracil coated with polysaccharides and their cell-specific cytotoxicity. Pure Appl Chem., 31: 629-642.

18. Peters P, Warren $K$ (1969): A rapid method of infecting mice and other laboratory animals with Schistosoma mansoni: Subcutaneous injection. J Parasitol., 55, 3:558-63.

19. Duvall R, DeWitte W (1967): An improved perfusion technique for recovering adult schistosomes from laboratory animals. Am J Trop Med Hyg., 16: 4:483-6.

20. Pellegrino J, Oliveria C, Faria J et al. (1962): New approach to the screening of drugs in experimental Schistosomiasis mansoni in mice. American Journal of Tropical Medicine and Hygiene, 11: 201-215.

21. Cheever A (1968): Conditions affecting the accuracy of potassium hydroxide digestion techniques for counting Schistosoma mansoni eggs in tissues. Bull WHO., 39, 2:32-8.

22. Bancroft J, Stevens A (1996): Theory and practice of histological techniques. $6^{\text {th }}$ ed Edinburgh: Churchill Livingstone,

Pp.744. https://www.elsevier.com/books/theory-and-practiceof-histological-techniques/bancroft/978-0-443-102790

23. Mahmoud A, Warren K (1974): Anti-inflammatory effect of tartaremetic and niridazole suppression of schistosoma egg granuloma. Journal of Immunology, 112: 222-228.

24. Spiegel R (1981): Theory and problems of statistics, Schaum's outline series. McGraw-Hill, Singapore. Pp.
549. http://www.fulviofrisone.com/ attachments/ article/

447/Schaum's\%20Outline\%20of\%20Statistic.pdf

25. WHO (2015): Esquistosomiasis.

https://www.who.int/health-topics/

schistosomiasis \#tab=tab_1

26. Doenhoff M, Hagan P, Cioli D et al. (2009): Praziquantel: its use in the control of schistosomiasis in sub-Saharan Africa and current research needs. Parasitology, 136(13):1825-1835.

27. Sadek G, Harba N, Elrefai S et al. (2018): Efficacy of praziquantel-loaded chitosan nanoparticles against both adult and schistosomula stages of Schistosoma mansoni. Journal of the Egyptian Society of Parasitology, 48(3): 629-638.

28. Abououf E, El Hamshary A, Nagati I et al. (2018): Effect of Nigella sativa oil on Schistosoma mansoni mature worms in experimentally infected mice. Journal of the Egyptian Society of Parasitology, 48(1): $55-66$.

29. EL Shenawy N, Soliman M, Reyad S (2008): The effect of antioxidant properties of aqueous garlic extract and Nigella sativa as anti- schistosomiasis agents in mic. Rev Inst Med Trop S Paulo, 50(1): 2936.

30. Warren K, Boros D (1975): The Schistosome egg granuloma: form of cell-mediated immunity. In: Furth RV (ed) Mononuclear phagocytes in immunity, infection, and pathology, Blackwell Scientific Publications, Oxford, Pp. 112.

31. Homeida M, Tom I, Nash T et al. (1991): Association of the therapeutic activity of praziquantel with the reversal of Symmers' fibrosis induced by Schistosoma mansoni. Am J Trop Med Hyg., 45:360-365.

32. Warren K (1996): The pathogenesis of clay-pipe-stem cirrhosis in mice with chronic schistosomiasis. Am J Path., 49:477-489.

33. Pearce E (2005): Priming of the immune response by Schistosome eggs. Parasite Immunol., 27(7-8):265270.

34. Sheir S, Maghraby A, Mohamed A et al. (2015): Immunomodulatory and ameliorative role of Nigella sativa oil on Schistosoma mansoni infected mice. Canadian J Pure Appl Sci., 9:3345-3355.

35. Kamel G, Metwally A, Guirguis F et al. (2000): Effect of a Combination of the New Antischistosomal Drug Ro 15-5458 and Praziquantel on Different Strains of Schistosoma mansoni Infected Mice. Arzneimittelforschung., 50: 391-394. 